\title{
Tinjauan Pembelajaran IPA melalui Evaluation Discrapancy Models
}

Submit: 16 Desember $2020 \quad$ RevisI: 24 Oktober $2021 \quad$ Terbit: 25 Oktober 2021

\author{
Yuniara1; Rita Sari2; Nina Rahayu ${ }^{3}$ \\ 1Mahasiswa PGMI IAIN Langsa, ${ }^{23}$ Dosen IAIN Langsa \\ yuniara@gmail.com; ritasari17@iainlangsa.ac.id; ninarahayu@iainlangsa.ac.id
}

\begin{abstract}
Learning Implementation Plan or RPP is a teaching device that must be prepared by teachers before conducting the teaching and learning process so that the results obtained can be taken into account in advance. With this preparation, it is expected that the learning process also runs systematically and follows the desired stages. The purpose of this study is to validate IPA learning by using discrepancy evaluation models in MIS Paya Bujok Tunong. This research uses a type of descriptive qualitative research. The results of the study found that some planned items were not carried out, in implementation activities, the chosen approach was not all implemented, teachers also did not use learning media, and assessment only focused on aspects of knowledge.
\end{abstract}

Keywords: Discrepancy Evaluation Models, Madrasah Ibtidaiyah, IPA Learning, Students.

\section{Abstrak}

Rencana Pelaksanaan Pembelajaran atau RPP adalah perangkat ajar yang harus disiapkan guru sebelum melakukan proses belajar mengajar agar hasil yang diperoleh dapat diperhitungkan sebelumnya. Dengan adanya persiapan ini diharapkan proses pembelajaran juga berjalan secara sistematis dan sesuai dengan tahapan yang diinginkan. Tujuan penelitian ini adalah untuk mengevaluasi pembelajaran IPA dengan menggunakan discrepancy evaluation models di MIS Paya Bujok Tunong. Peneliti menggunakan jenis penelitian kualitatif deskriptif. Hasil penelitian menemukan bahwa beberapa item yang direncanakan tidak terlaksana, pada kegiatan pelaksanaan, pendekatan yang dipilih tidak semuanya diimplementasikan, guru juga tidak menggunakan media pembelajaran, dan penilaian hanya berfokus pada aspek pengetahuan saja.

Kata Kunci: Discrapancy Evaluation Models, Madrasah Ibtidaiyah, Pembelajaran IPA, Siswa. 


\section{PENDAHULUAN}

Interaksi yang terjadi antara guru dan siswa dalam kelas sangat menentukan proses dan hasil belajar siswa. Kemampuan guru mentransformasikan pesan pembelajaran dengan baik merupakan syarat mutlak yang tidak dapat ditawar lagi (Sari, 2017). Dengan demikian tentu diperlukan persiapan yang matang dalam penyusunan rencana mengajar, pelaksanaan dan penilaian pembelajaran.

Komponen pembelajaran terdiri dari tujuh komponen yakni peserta didik, guru, tujuan pembelajaran, isi pelajaran, metode mengajar, RPP dan media (Djamarah, 2010). Di antara tujuh komponen tersebut, maka tugas guru sebelum memulai pembelajaran adalah menyiapkan RPP, menentukan tujuan, metode dan media ajar, serta meramu isi pelajaran agar mudah diterima oleh siswa. Sebab kegiatan belajar mengajar tidak selamanya berjalan dengan baik/lancar, terdapat beberapa kendala yang ditemukan terbatasnya waktu dalam suatu pertemuan di kelas akan membuat guru tidak maksimal dalam menemukan dan melayani siswa, selain itu adalah kemampuan siswa yang beragam dan fasilitas pendukung belajar yang tidak memadai (Syah, 2012).

Namun pada kenyataannya, guru MIS Paya Bujok Tunong tidak menyiapkan RPP namun menyadur dari sumber lain, karena menurut mereka, materi sudah dikuasai sebab bertahun-tahun itu saja yang diajarkan. Metode yang digunakan hanya ceramah dan bertanya kepada siswa, sehingga pembelajaran hanya berlangsung dua arah. Semestinya sebelum mengajar, guru menyiapkan lima komponen pembelajaran yang sesuai dengan karakteristik siswa dan sepatutnya proses belajar mengajar dapat dilakukan secara multi arah dengan melibatkan media ajar. Terlebih pada pembelajaran IPA yang harus dibelajarkan dengan sistematis, guru perlu mengajarkan langkah-langkah ilmiah yang didasarkan pada pengamatan (Sari, 2017). Oleh karena itu, pada penelitian ini akan ditelusuri secara mendalam bagaimana perencanaan, proses, dan penilaian yang dilakukan oleh guru di MIS Paya Bujok Tunong Kota Langsa dengan menggunakan discrapancy evaluation models (DEM). 


\section{METODE PENELITIAN}

Dalam penelitian ini, peneliti menggunakan jenis penelitian kualitatif deskriptif (Prastowo, 2016). Data yang digunakan berupa perangkat ajar yang disiapkan guru, yang kemudian dianalisis untuk menemukan kesenjangan antara kenyataan dan harapan sesuai dengan tahapan DEM (Sari \& Srimuliati, 2019).

\section{HASIL DAN PEMBAHASAN}

\section{Analisis Rencana dan Pelaksanaan Pembelajaran}

\section{Penetapan Standar}

Standar yang ditetapkan mengunakan standar dari Kementerian Agama sesuai dengan ruang lingkup sekolah tersebut yaitu Madrasah Ibtidaiyah ( MI ). Komponen RPP berupa Kompetensi Inti, Kompetensi Dasar, Indikator, Tujuan Pembelajaran, Materi Pembelajaran, Pendekatan dan Metode, Kegiatan Pembelajaran, Penilaian dan Sumber Belajar. Adapun RPP yang disusun oleg guru ditampilkan seperti gambar 1. di bawah ini:
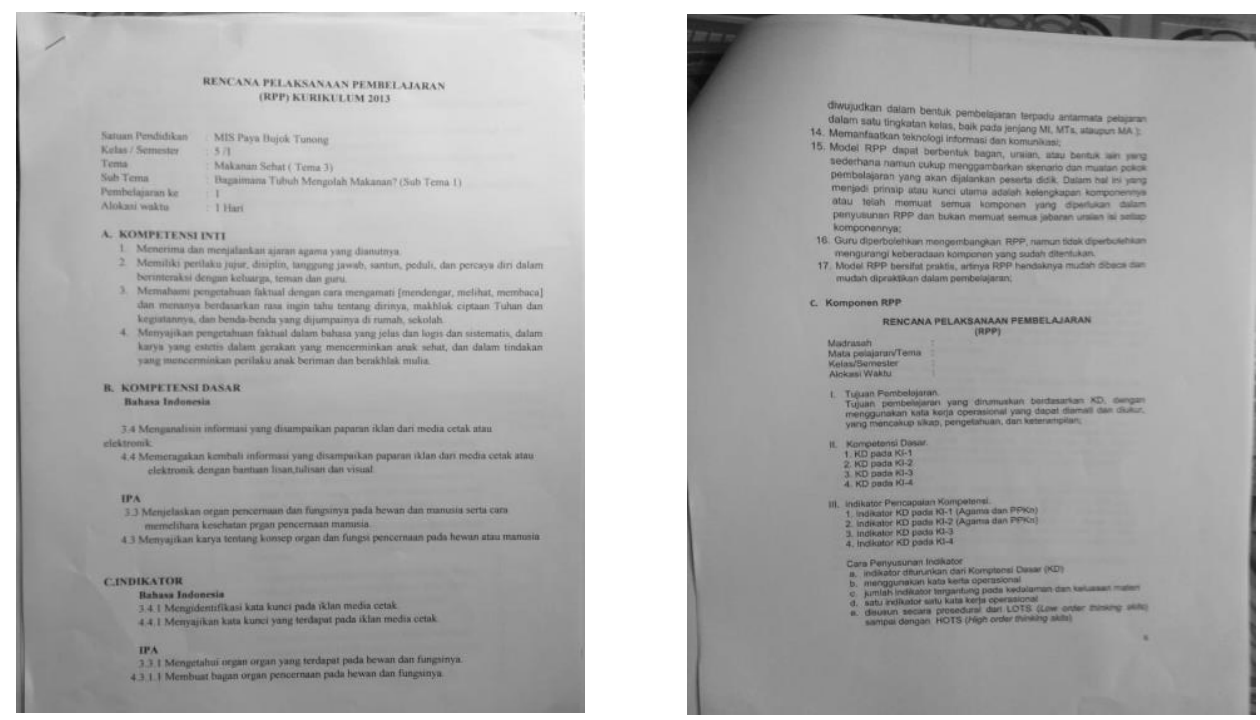

Gambar 1. RPP Guru MIS Paya Bujok Tunong

\section{Analisa terhadap Kompetensi Inti:}

Pada saat proses pembelajaran guru menjelaskan materi ajar berupa makanan sehat, pada saat membuka pelajaran, guru mengajak siswa untuk bersyukur kepada Allah atas pemberian nikmat berupa makanan (KI-1). Berikutnya guru meminta siswa

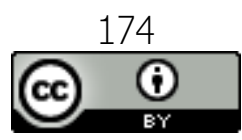


agar selalu berlaku jujur, disiplin, tanggung jawab, santun, peduli dan percaya diri dalam berinteraksi dalam proses pembelajaran. Namun masih ditemukan ada siswa yang tidak jujur dalam proses pembelajaran yakni siswa masih ada yang menyontek ketika diberi tugas (KI-2). Kemudian guru mengunakan pendekatan saintifik dalam proses pembelajaran. Namun pada pelaksanaannya, guru mengunakan metode ceramah, tanya jawab, penugasan, dan media berupa buku panduan (KI-3). Terakhir adalah guru menyajikan pengetahuan faktual dalam bahasa yang jelas logis, dan sistematis dalam karya estetis dalam gerakan yang mencerminkan anak sehat, dan dalam tindakan yang mencerminkan perilaku anak beriman dan berakhlak mulia, namun dalam proses pembelajaran, tidak ditemukan kegiatan praktik atau simulasi tentang makanan sehat (KI-4).

\section{Analisa terhadap Kompetensi Dasar}

KD. 3.3. Menjelaskan organ pencernaan dan fungsinya pada hewan dan manusia serta cara memelihara kesehatan organ pencernaan manusia.

Guru sepatutnya menjelaskan tentang organ pencernaan dan fungsinya pada hewan dan manusia serta cara memelihara kesehatan organ pencernaan manusia. Namun guru hanya menjelaskan tentang organ pencernaan hewan, fungsi dan jenisnya. Materi tentang cara memelihara kesehatan organ pencernaan tidak disampaikan.

KD. 3.4. Menganalisis informasi yang disampaikan paparan iklan dari media cetak atau elektronik.

Guru harus menganalisis informasi yang disampaikan paparan iklan dari media cetak atau elektronik. Pada pelaksanaannya analisis informasi yang disajikan guru berasal dari paparan iklan di buku panduan tanpa menambah sumber asli dari media cetak dan elektonik.

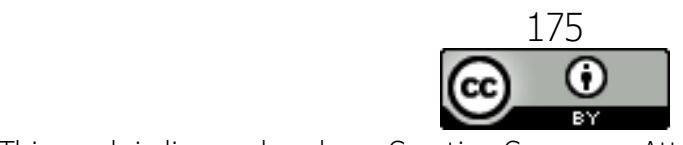


KD. 4.3. Menyajikan karya tentang konsep organ dan fungsi pencernan hewan dan manusia.

Guru mesti mengajak siswa untuk menyajikan karya tentang konsep organ dan fungsi pencernaan hewan dan manusia. Namun tidak ada karya yang ditampilkan siswa dari hasil diskusi atau temuan sederhana tentang konsep organ pencernaan hewan dan fungsi organ pencernaan.

KD. 4.4. Memeragakan kembali informasi yang disampaikan paparan iklan dari media cetak atau elektronik dengan bantuan lisan, tulisan dan visual.

Guru harus memperagakan kembali informasi yang disampaikan paparan iklan dari media cetak dan elektronik dengan bantuan lisan, tulisan dan visual. Tetapi pada saat pelaksanaan tidak ada peragaan informasi paparan iklan baik itu secara lisan, tulisan dan visual yang dilakukan oleh guru atau siswa.

\section{Analisa terhadap Indkator}

3.3.1. Mengetahui organ-organ yang terdapat pada hewan dan fungsinya.

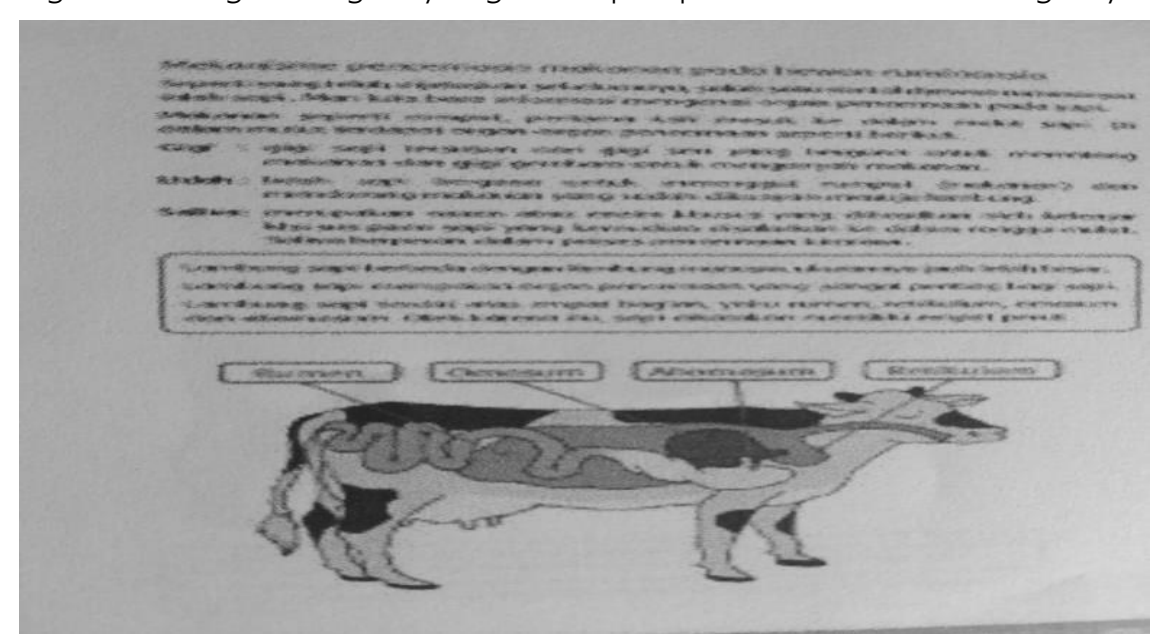

Gambar 2. Organ-Organ Hewan dan Fungsinya

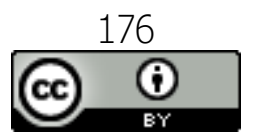

This work is licensed under a Creative Commons Attribution 4.0 International License 
Pada indikator ini, guru telah menjelaskan organ-organ hewan dan fungsinya pada siswa. Sehingga indikator 3.3.1. telah terpenuhi.

Indikator 3.4.1 Mengidentifikasi kata kunci pada iklan media cetak.

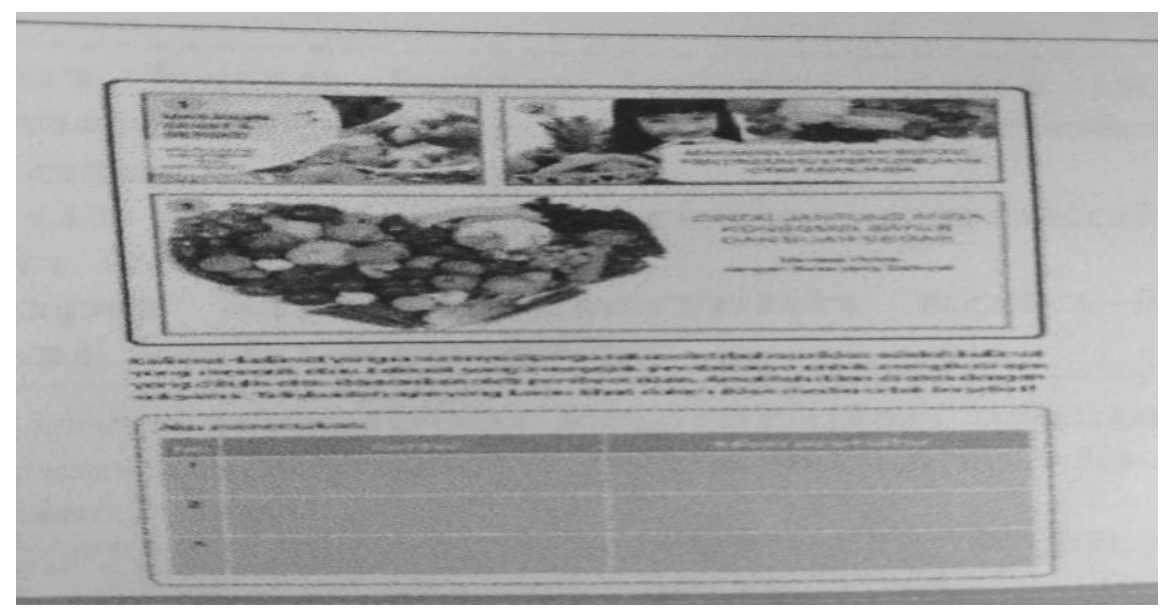

Gambar 3. Identifikasi Kata Kunci Iklan pada Buku Panduan
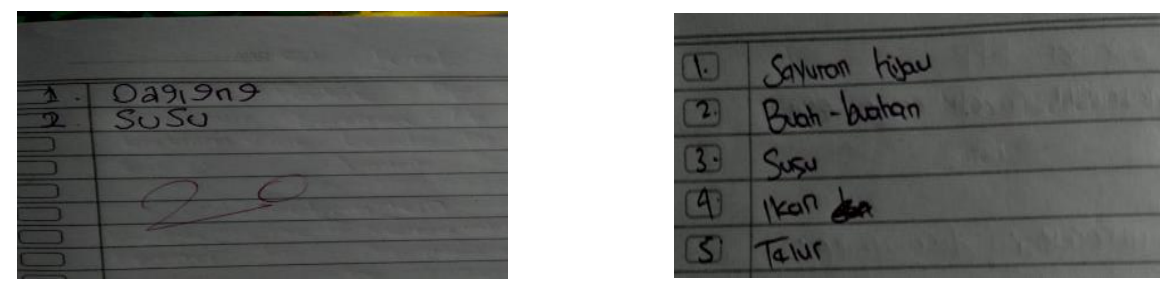

Gambar 4. Hasil Tugas Siswa dalam Menemukan Kata Kunci Iklan

Guru meminta siswa untuk mengidentifikasi kata kunci pada iklan media cetak. Masih terdapat dua orang siswa yang kurang mampu menemukan kata kunci pada iklan media cetak di buku panduan. Namun sebagian besar siswa sudah mampu menemukan kata kunci iklan tersebut.

Indikator 4.3.1. Membuat bagan organ pencernaan pada hewan dan manusia.

Guru bersama siswa seharusnya membuat bagan organ pencernaan pada hewan dan fungsinya. Namun tidak ditemukan siswa yang membuat bagan organ pencernaan pada hewan dan fungsinya, melainkan siswa hanya menyelesaikan soal saja.

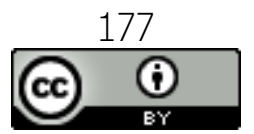


Indikator 4.4.1 Menyajikan kata kunci yang terdapat pada iklan media cetak.

Pada pelaksanaan pembelajaran guru tidak menyajikan cara menemukan kata kunci yang terdapat pada iklan media cetak. Sehingga hal inilah yang menjadi salah satu penyebab siswa sulit mencari kata kunci dari iklan.

\section{Analisa terhadap Tujuan Pembelajaran}

TP-1: Dengan mengamati gambar iklan yang disajikan, siswa mengedidentifikasikan kata kunci pada iklan media cetak.

Siswa mengamati gambar iklan yang disajikan pada buku panduan dan mengidentifikasi kata kunci pada iklan media cetak.

TP-2: Dengan menuliskan hasil pengamatan terhadap iklan media cetak dalam bentuk peta pikiran, siswa mampu melaporkan hasil pengamatanya.

Guru hanya meminta siswa menemukan kata kunci dan menuliskannya serta melaporkan kata kunci yang sudah mereka temukan. Namun guru tidak meminta siswa untuk membuat peta pikiran tentang makanan sehat dari kata kunci yang sudah ditemukan siswa.

TP-3: Dengan mencermati teks bacaan yang sisajikan, siswa mampu menemukan informasi tentang organ-organ pencernaan hewan.

Siswa hanya membaca teks tentang makanan sehat dan tidak ada tindak lanjut misalnya berupa pelaporan atau presentasi hasil kerja mereka.

TP-4: Dengan berdiskusi dan mencari informasi dalam kelompok, siswa mampu menjelaskan organ-organ pencernaan hewan dan fungsinya.

Guru tidak membuat kelompok diskusi, sehingga TP-4 ini sama sekali tidak terlaksana.

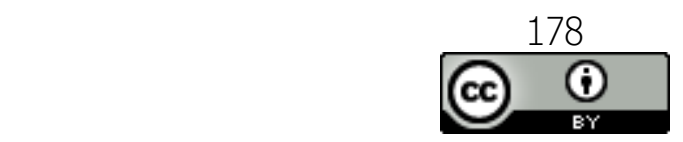




\section{Analisa terhadap Materi Ajar}
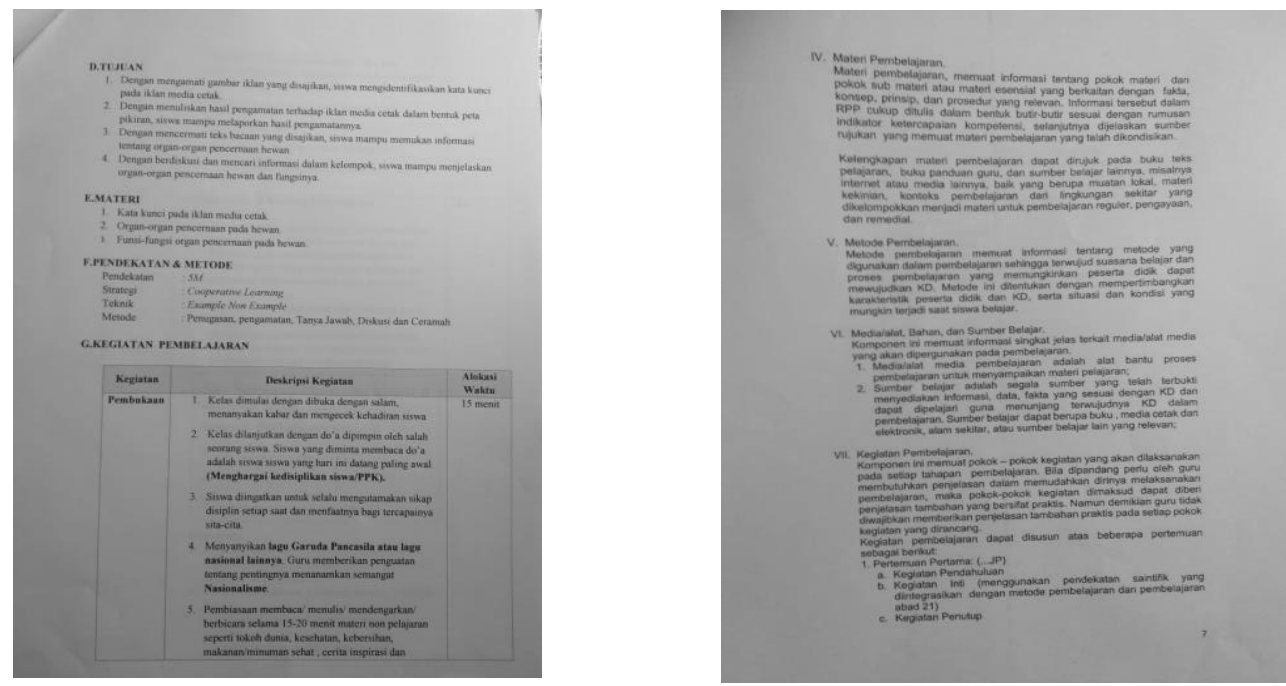

Gambar 5. RPP Guru yang memuat Materi Ajar

Materi ajar dari Tema Makanan Sehat adalah (1) Kata kunci pada iklan media cetak; (2) Organ-organ pencernaan pada hewan; dan (3) Fungsi-fungsi organ pencernaan pada hewan. Informasi yang disajikan dalam RPP gur, telah memuat butiran-butiran sesuai dengan rumusan indikator dan materi ajar sesuai dengan silabus yang ada. Pada pelaksanaannya, guru menyampak ketiga materi ajar tersebut, meskipun ada beberapa hal dari setiap KD, Indikator, atau tujuan pembelajaran yang belum sesuai standar.

\section{Analisa terhadap Pendekatan, Strategi, Metode, dan Teknik Pembelajaran}

Pendekatan pembelajaran yang tertulis di RPP adalah pendekatan saintifik atau lebih dikenal dengan 5M (Mengamati, Menanya, Mengumpulkan informasi, Mengasosiasi dan Mengomunikasikan). Pada prosesnya hanya 3M saja yang terlaksana, yaitu mengamati, menanya dan mengumpulkan informasi.

Strategi yang direncanakan adalah Cooperative Learning. Namun pada proses belajar mengajar tidak ditemukan implementasi strategi Cooperative Learning, karena siswa diminta bekerja secara individual. Metode yang direncanakan adalah penugasan, tanya jawab, diskusi, dan ceramah. Dari empat metode yang direncanakan, terdapat satu metode yang tidak dilakanakan, yaitu metode diskusi.

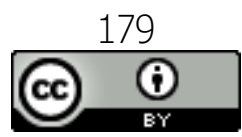

This work is licensed under a Creative Commons Attribution 4.0 International License 
Sedangkan teknik pembelajaran yang digunakan adalah example non example. Teknik ini mengkombinasikan antara materi dengan sejumlah contoh berupa gambar yang sesuai dengan materi, dengan mengunakan teknik ini siswa dapat secara langsung melihat gambar dan belajar memahami materi sangat mudah. Namun guru hanya menyajikan contoh berupa gambar-gambar yang ada di buku panduan saja.

\section{Analisa terhadap Kegiatan Pembelajaran}

Kegiatan pembelajaran berfokus kepada 5M yaitu mengamati, menaya, mengumpulkan informasi, mengasosiasi, dan mengkomunikasi. Dalam tahap menanya guru mengajak siswa untuk melihat gambar buah-buahan yang disajikan dalam buku, selanjutnya guru bertanya mengajukan beberapa pertanyaan seperti "menurut kamu apakah serapan itu penting? Apa yang kamu ketahui tentang makanan sehat?". Kemudian ada siswa yang bertanya "apa itu makanan sehat bu? Bu, bagaimana bentuk organ pencernaan hewan?"

Kemudian siswa mengamati gambar iklan makanan sehat, setelah mencermati teks bacaan, siswa mencatat apa saja makanan sehat yang terdapat dalam iklan tersebut. Namun tidak ada kerja kelompok dan membuat bagan pikiran dari kata kunci yang sudah ditemukan oleh siswa.

\section{Analisa terhadap Penilaian}
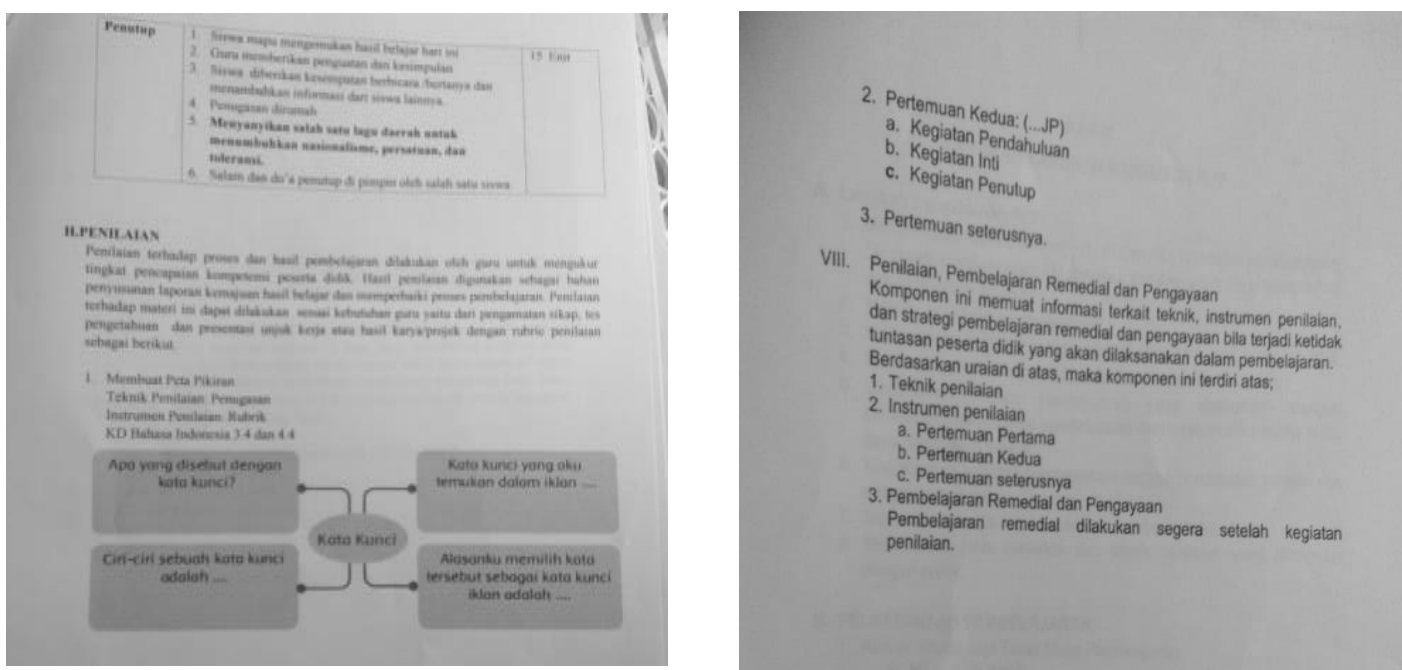

Gambar 6. Rencana Penilaian Pembelajaran

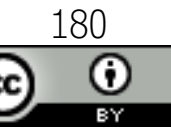

This work is licensed under a Creative Commons Attribution 4.0 International License 
Penilaian semestinya mencakup penilaian sikap, tes pengetahuan dan keterampilan. Namun kenyataanya di kelas guru hanya menentukan dari aspek pengetahuan saja.

\section{Analisa terhadap Sumber Belajar}

Satu-satunya sumber belajar yang digunakan guru hanya buku pelajaran yang tersedia di sekolah. Hal ini tentunya memudahkan siswa dalam belajar, namun kekurangannya adalah siswa tidak mendapatkan pembanding dari sumber lain untuk menambah wawasan mereka.

\section{Analisa terhadap Pelaksanaan}

Temuan penelitian menunjukkan bahwa guru merancang RPP namun pada pelaksanaannya ada yang terlewati atau tidak dilaksanakan. Guru tidak menjelaskan tujuan pembelajaran, seharusnya hal ini dijelaskan di awal pembelajaran agar siswa termotivasi untuk mempelajari materi yang disajikan serta aktif selama proses pembelajaran berlangsung.

Pendekatan yang direncanakan 5M hanya terlaksana 3M saja, demikian pula dengan strategi cooperative learning yang tidak dilaksanakan, tatkala guru tidak merancang strategi yang membuat siswa aktif, mengakibatkan siswa akan sulit memahami materi yang diajarkan guru. Metode diskusi juga tidak terlaksana, serta teknik example non example yang belum optimal.

Media ajar juga tidak direncanakan sebelumnya oleh guru, jadi sumber belajar satu-satunya hanya berupa buku panduan yang disediakan sekolah. Padahal, media sangat dibutuhkan agar siswa dapat melihat secara langsung contoh-contoh materi yang sedang dipelajari. Hal ini juga mendukung siswa untuk lebih aktif dalam memberi contoh lain yang mereka temukan dalam kehidupan sehari-hari. Terlebih media juga digunakan untuk mempermudah guru untuk mengambil alih perhatian siswa selama proses pembelajaran berlangsung.

Guru yang berkompeten akan selalu menguasai kelas dan mencoba memahami apa yang dibutuhkan siswa saat belajar di kelas. Siswa terkadang terampil belajar 
sendiri, ada yang suka mengganggu teman sebangkunya dan sebagainya. Hal ini merupakan tugas guru untuk mengelola kelas agar situasi dapat terorganisir dengan baik. Untuk menstimulus penguasaan kelas, guru juga aktif bertanya jawab kepada siswa. Hal ini dilakukan agar siswa selalu fokus pada materi yang disampaikan dan guru tidak membiarkan siswa belajar sendiri di kelas. Dengan kata lain, guru selalu berinteraksi kepada siswa tentang apa yang siswa tidak paham mengenai materi yang sedang dipelajari. Upaya ini harus terus dilakukan agar pencapaian tujuan pembelajaran dapat dicapai sesuai dengan apa yang diharapkan.

\section{Analisa terhadap Evaluasi}

Setelah semua upaya dilakukan, pada tahap akhir guru memberikan soal tes kepada siswa sebagai upaya untuk mengevaluasi. Evaluasi ini dilakukan untuk melihat sejauh mana siswa memahami materi yang telah diajarkan dan untuk melihat kesulitan-kesulitan apa saja yang siswa hadapi setelah mempelajari materi makanan sehat dengan sub tema bagaimana tubuh mengolah makanan. Namun evaluasi yang diberikan guru hanya berupa aspek pengetahuan saja tanpa melihat aspek sikap dan keterampilanya.

\section{KESIMPULAN}

Perencanaan pembelajaran yang dibuat seharusnya dapat dilakukan secara praktis, sehingga dalam membuat rencana, guru harus memikirkan secara komprehensif kesesuaian pendekatan, strategi, metode, teknik, dan media yang akan digunakan agar bersesuaian dengan materi ajar yang rumit seperti pembelajaran IPA, juga cocok diimplementasikan bagi siswa usia dasar. 


\section{DAFTAR PUSTAKA}

Djamarah, S. B. (2010). Guru Dan Anak Didik Dalam Interaksi Edukatif (Suatu Pendekatan Teoritis Psikologis. Jakarta: PT. Rineka Cipta.

Moleong, L. J. (2017). Metodologi Penelitian Kualitatif. Jakarta: Remaja Rosda Karya.

Prastowo, A. (2016). Metode Penelitian Kualitatif dalam Perspektif Rancangan. Jurnal Fokus Konseling, 2(2).

Sari, R. (2017). Paradigma Scaffolding: Alternatif Pembelajaran Sains Sebagai Stimulus Siswa Sadar Lingkungan DI SDIT Lukmanul Hakim Langsa. BioLink: Jurnal Biologi Lingkungan, Industri dan Kesehatan, 4(1). Retrieved from http://ojs.uma.ac.id/index.php/biolink

Sari, R. (2017). Pengantar Penelitian Kuantitatif. Yogyakarta: Deepublish.

Sari, R. (2018). Motivasi berprestasi, kepuasan kerja dan manajerial kepala sekolah serta dampaknya terhadap kinerja guru. Mahesa Research Institute, 16-19. Retrieved from http://mahesainstitute.web.id/ojs2/index.php/jehss/article/view/3

Sari, R., \& Srimuliati, S. (2019). Analisa Kompetensi Alumni Pendidikan Matematika menggunakan Discrapancy Evaluation Model. 6(1). doi:https://doi.org/10.32505/tarbawi.v11i1.1026

Sari, R., Nuraida, \& Rizki, S. (2017). Think Pair Share: Alternatif Peningkatan Aktivitas dan Hasil Belajar IPA. PeTeKa (Jurnal Penelitian Tindakan Kelas dan Pengembangan Pembelajaran), 1(1).

Syah, M. (2012). Psikologi Pendidikan Suatu Pendekatan Baru. Bandung: Remaja Rosda Karya. 
